\title{
Response to: Non-invasive electrical brain stimulation induces vision restoration in patients with visual pathway damage
}

\author{
Florian Gekeler • Karl Ulrich Bartz-Schmidt
}

Received: 29 May 2012 / Accepted: 31 May 2012 /Published online: 23 June 2012

(C) Springer-Verlag 2012

Dear Mrs. Gall, Mrs. Antal, and Mr. Sabel,

Thank you for supplementing our editorial on electrical stimulation of the retina and optic nerve with your own data on electrical stimulation of the brain. We regret that we had to omit several citations in our editorial. In a developing research field with increasing interest of colleagues and patients, naturally also accompanied by justified critical voices, we feel that it is absolutely crucial to assess safety and efficacy using standardized testing equipment and openly discuss findings. We also believe that in order to make results repeatable, stimulating parameters should be readily accessible to the research community and not fall behind commercial interests. Only this can ensure a fruitful scientific discussion and potentially give electrical stimulation treatment an accepted role in the treatment of patients.

F. Gekeler $(\bowtie)$

Ophthalmology, University Hospital,

Schleichstrasse 12-16,

Tuebingen 72076, Germany

e-mail: gekeler@uni-tuebingen.de

F. Gekeler

e-mail: fgekeler@googlemail.com

F. Gekeler $\cdot$ K. U. Bartz-Schmidt

Centre for Ophthalmology, University of Tübingen,

Tübingen, Germany 